\title{
A specialised delivery system for stratospheric sulphate aerosols (part 2): financial cost and equivalent $\mathrm{CO}_{2}$ emission
}

\author{
I. E. de Vries ${ }^{1}$ - M. Janssens ${ }^{2}$ • S. J. Hulshoff ${ }^{2}$. DSE 16-02
}

Received: 25 July 2019 / Accepted: 24 February 2020 / Published online: 6 May 2020

(C) The Author(s) 2020

\begin{abstract}
Temporary stratospheric aerosol injection (SAI) using sulphate compounds could help avoid some of the adverse and irreversible impacts of global warming, but comprises many risks and uncertainties. Among these, the direct financial cost and carbon emissions of potential SAI delivery systems have hitherto received only modest attention. Therefore, this paper quantifies the initial and operating financial costs and initial and operating equivalent $\mathrm{CO}_{2}$ $\left(\mathrm{CO}_{2}\right.$ eq) emissions of the specialised aircraft-based SAI delivery system developed with relatively high-fidelity tools in part 1 of this series. We analyse an interval of operating conditions, within which we devote special attention to four injection scenarios outlined in part 1: Three scenarios where $\mathrm{H}_{2} \mathrm{SO}_{4}$ vapour is directly injected at several dispersion rates and one $\mathrm{SO}_{2}$ injection scenario. We estimate financial cost through Raymer's adjustment of Rand Corporation's Development and Production Costs for Aircraft (DAPCA) model, augmented by additional data. $\mathrm{CO}_{2}$ eq emission is computed from existing data and the computed fuel consumption for each of the scenarios. The latter estimates include an emission weighting factor to account for non- $\mathrm{CO}_{2}$ aircraft combustion products at altitude. For direct $\mathrm{H}_{2} \mathrm{SO}_{4}$ injection, both financial cost and $\mathrm{CO}_{2}$ eq emission are sensitive to the design dispersion rate. For scenarios where higher dispersion rates are achieved, the delivery system's cost and $\mathrm{CO}_{2}$ eq are relatively small compared with the presumed benefits of SAI. The most optimistic $\mathrm{H}_{2} \mathrm{SO}_{4}$ scenario is found to have a financial cost and $\mathrm{CO}_{2}$ eq emission similar to that of $\mathrm{SO}_{2}$ injection, while potentially allowing for reductions in the annual mass of sulphur injected to achieve a target negative radiative forcing. The estimates of financial cost and $\mathrm{CO}_{2}$ eq emission were subjected to sensitivity analyses in several key parameters, including aircraft operational empty weight, engine specific fuel consumption, fuel price and aerosol price. The results indicate that the feasibility of the considered scenarios is robust.
\end{abstract}

Electronic supplementary material The online version of this article (https://doi.org/10.1007/s10584-020-02686-6) contains supplementary material, which is available to authorized users.

Design Synthesis Exercise 2016 - Group 02: M. Cruellas Bordes, C. J. G. De Petter, A. F. van Korlaar, L. P. Kulik, R. Maselis, L. H. Mulder, S. Stoev, K. J. F. van Vlijmen, C. H. Melo Souza, D. Rajpal

S. J. Hulshoff

s.j.hulshoff@tudelft.nl

Extended author information available on the last page of the article. 


\section{Introduction}

If emission of greenhouse gases and associated global warming proceed along a high Representative Concentration Pathway (RCP) (IPCC 2018), one may consider enacting temporary measures to limit further increases in the probability and severity of adverse and irreversible impacts of continued climate change, until emission reductions and potential carbon capture efforts have returned the greenhouse gas concentration in the atmosphere to safe levels. Although they are by no means suggested to be a solution to the climate change problem, such temporary measures could include solar radiation management (SRM) techniques such as cirrus cloud thinning (Storelvmo et al. 2013; Lohmann and Gasparini 2017) (CCT), marine cloud brightening (Latham et al. 2012) (MCB) and stratospheric aerosol injection (Crutzen 2006) (SAI). While SAI is generally regarded as the most feasible option (Shepherd 2009), it comes with a long list of risks and uncertainties (Robock 2014), spanning i.a. the environmental (Kravitz et al. 2013), social (Irvine et al. 2016), ethical (Lin 2013), policy (Reynolds 2019) and technical domains. Here, we focus on the financial and environmental implications of developing and operating a delivery system capable of lifting very large payloads to unconventionally high altitudes.

McClellan et al. (2010) and Smith and Wagner (2018) propose specially developed aircraft for delivering aerosol precursors to the stratosphere. They estimate that these likely form realistic delivery platforms at a manageable financial cost per injected unit mass. Part 1 of this series corroborated the technical viability of specialised aircraft delivery systems by designing a fleet of aircraft and its operation at a higher degree of technical fidelity than these studies. However, it did not yet quantify the delivery system's financial cost. In this second part of the series, we therefore perform a detailed analysis of the financial costs for developing and operating this delivery system ${ }^{1}$.

Furthermore, neither McClellan et al. nor Smith and Wagner address the contribution to the atmospheric greenhouse gas concentration of developing, producing and operating a large fleet of aircraft for SAI (McClellan et al. 2010; Smith and Wagner 2018). However, in order to make a full assessment of the risks and benefits of SAI, it is imperative to establish the carbon footprint of proposed delivery systems. Therefore, this paper will also quantify the equivalent $\mathrm{CO}_{2}\left(\mathrm{CO}_{2} \mathrm{eq}\right)$ emissions incurred by initially conceiving and operating the delivery system proposed in part 1 .

Part 1 addressed four operating scenarios: Three featuring direct injection of $\mathrm{H}_{2} \mathrm{SO}_{4}$ vapour along with one $\mathrm{SO}_{2}$ injection scenario. The $\mathrm{H}_{2} \mathrm{SO}_{4}$ scenarios are advantageous in that they offer the potential of maximising the effectiveness of SAI per unit mass of injected S (Vattioni et al. 2019). However, they might also require greater technical resources. As a result, it is unclear whether their deployment-related financial costs and $\mathrm{CO}_{2}$ eq emissions are competitive with respect to $\mathrm{SO}_{2}$ injection. Therefore, we analyse and compare the financial cost and $\mathrm{CO}_{2}$ eq emission of each of the SAI scenarios developed in part 1 .

The paper first briefly describes the SAI system and injection scenarios developed in part 1. This is followed by analyses of the financial cost and $\mathrm{CO}_{2} \mathrm{eq}$ emission over an interval of dispersion rates that encompass the injection scenarios. These analyses are accompanied by descriptions of their respective estimation methods. Finally, the sensitivity of financial cost and $\mathrm{CO}_{2}$ eq emission to several important input parameters subject to uncertainty is examined.

\footnotetext{
${ }^{1}$ The current analysis differs from the preliminary one in DSE Group 02 (2016) and cited by Smith and Wagner (2018) in that it includes an updated and more detailed cost model.
} 


\section{Summary of the delivery system}

The following subsections summarise the features of the SAI delivery system developed in part 1 salient for the analysis of financial cost and $\mathrm{CO}_{2}$ eq. The design choices and factors concerning aerosol material and delivery are first outlined, followed by the candidate injection scenarios. Then, the most important aspects of the aircraft and flight profiles that emerge from these scenarios are highlighted.

\subsection{Aerosol and delivery requirements}

In order to facilitate realistic estimates of financial cost and $\mathrm{CO}_{2}$ eq emission, the delivery system considered here is based on the use of sulphate aerosols. These grow naturally in the stratosphere after volcanic eruptions, leading to relative certainty concerning their impacts on temperature and the climate system (Pope et al. 2012; Keith et al. 2016; Dykema et al. 2016). Sunlight-scattering sulphate aerosols in the stratosphere consist of $\mathrm{H}_{2} \mathrm{SO}_{4}$ particles. These can be introduced into the atmosphere either by injection of precursor compounds, such as $\mathrm{SO}_{2}$, or by directly injecting condensable $\mathrm{H}_{2} \mathrm{SO}_{4}$. Part 1 of this study discusses how direct $\mathrm{H}_{2} \mathrm{SO}_{4}$ injection appears promising with respect to $\mathrm{SO}_{2}$ injection, as it facilitates targeting the growth of optimally sized aerosols. While direct comparisons between $\mathrm{SO}_{2}$ and $\mathrm{H}_{2} \mathrm{SO}_{4}$ injection are relatively sparse and significant uncertainties in their long-term, large-scale application remain (Pope et al. 2012; Pierce et al. 2010; Benduhn et al. 2016; Vattioni et al. 2019), the potential benefits of direct $\mathrm{H}_{2} \mathrm{SO}_{4}$ injection make this the main focus of our aircraft-based delivery system.

To provide conservative measures of the costs and emissions of an SAI delivery system in a fully operational phase, we target a constant, rather large annual delivery rate of $15 \mathrm{Mt} \mathrm{H}_{2} \mathrm{SO}_{4} \mathrm{yr}^{-1}$ (5 Mt S yr${ }^{-1}$ ). This corresponds to contemporary estimates of the rates needed to achieve 2.5-3 $\mathrm{Wm}^{-} 2$ negative radiative forcing (IPCC 2018; Pierce et al. 2010; Vattioni et al. 2019). If desired, the target rate can be adapted by changing the fleet size of the delivery system. We estimate the sensitivity of our cost and emission figures to such modifications in Section 5. Here, we choose to focus on a single delivery rate for the sake of clarity. For effective, global radiation reduction, delivery will take place near altitudes of $20 \mathrm{~km}$ at latitudes centred around $15^{\circ}$ north and south (Rasch et al. 2008; Pierce et al. 2010; Tilmes et al. 2017; Vattioni et al. 2019).

Two parameters drive the growth of optimally sized particles (here we target initial particle sizes of approximately $0.1 \mu \mathrm{m}$ (Pierce et al. 2010)) from direct $\mathrm{H}_{2} \mathrm{SO}_{4}$ injection: the initial $\mathrm{H}_{2} \mathrm{SO}_{4}$ concentration in molecules $\mathrm{cm}^{-3}$ and background flow diffusivity (Benduhn et al. 2016). These two parameters can be related to financial cost and $\mathrm{CO}_{2}$ eq emission through dispersion rate $D R$ - the mass of aerosol dispersed per flown unit length-in $\mathrm{kg}$ $\mathrm{H}_{2} \mathrm{SO}_{4} \mathrm{~m}^{-1}$, which additionally depends on the volume flow rate of injection and aircraft speed. High $D R$ allows short flights with high payloads, which in turn is beneficial for minimising the operation's financial cost and emissions. The high initial $\mathrm{H}_{2} \mathrm{SO}_{4}$ concentrations associated with high $D R$ s require a high diffusivity for favourable initial particle growth (Benduhn et al. 2016). To achieve this, we propose dispersing the $\mathrm{H}_{2} \mathrm{SO}_{4}$ in a single engine's exhaust plume. However, the diffusivity in aircraft engine plumes is neither constant, uniform nor well-established (Yu and Turco 1998; Schumann et al. 1998). To capture the resulting uncertainty, part 1 of this study considered three direct $\mathrm{H}_{2} \mathrm{SO}_{4}$ injection scenarios with different combinations of diffusivity and initial concentration. We briefly introduce these below and refer the reader to part 1 for a more elaborate motivation on their choice. 
The lowest DR considered and upper bound to estimates of financial cost and $\mathrm{CO}_{2} \mathrm{eq}$ emission is set by the conservative core injection $(\boldsymbol{C I})$ scenario. This entails that the diffusivity is assumed to be low $\left(100 \mathrm{~m}^{2} \mathrm{~s}^{-1}\right)$ and that $\mathrm{H}_{2} \mathrm{SO}_{4}$ is only injected into the uniform, high-velocity core flow of the specialised turbofan engine of the aircraft. Targeting an initial particle radius of $\approx 0.1 \mu \mathrm{m}$ at the assumed diffusivity requires an initial $\mathrm{H}_{2} \mathrm{SO}_{4}$ concentration of approximately $10^{16} \mathrm{~cm}^{-3}$ (Benduhn et al. 2016), leading to a relatively low $D R$ of $0.002 \mathrm{kgm}^{-1}$.

The second full injection $(\boldsymbol{F I})$ scenario considers injection into the full engine flow to help increase $D R$. This is incommensurate with the plume simulations upon which we base our results, which assume a uniform, well-mixed initial flow (Pierce et al. 2010; Benduhn et al. 2016). Therefore, the viability of this scenario is somewhat less certain. However, owing to the higher total volume flow, it should achieve a $D R$ that is an order of magnitude higher $\left(0.02 \mathrm{kgm}^{-1}\right)$ than the $\boldsymbol{C I}$ scenario at the same assumed diffusivity and initial concentration. Therefore, we still consider it highly relevant to analyse the potential of such a scenario.

Improved engine flow mixing technology or more accurate measurements of plume growth might show that diffusivity values higher than those considered in the first two scenarios can be attained. This is likely, given that detailed engineering optimisations have yet to be performed for this purpose. Thus, the third, optimised full injection $(\boldsymbol{O F I})$ scenario considers a relatively high value of diffusivity, $3.16 \cdot 10^{2} \mathrm{~m}^{2} \mathrm{~s}^{-1}$, in combination with both core and bypass injection. This corresponds to a much higher initial $\mathrm{H}_{2} \mathrm{SO}_{4}$ concentration and $D R$ of $3.16 \cdot 10^{17} \mathrm{~cm}^{-3}$ and $0.5 \mathrm{kgm}^{-1}$, respectively.

When precursors such as $\mathrm{SO}_{2}$ are injected, aerosol formation does not occur until long after delivery and is thus virtually independent of $D R$. Hence, cost-efficient, short, highpayload flights can be employed. However, aerosol particles formed from $\mathrm{SO}_{2}$ injection have a lower radiative forcing efficiency, which we account for by assuming that approximately twice the amount of $\mathrm{S}$ is required when injecting $\mathrm{SO}_{2}$ instead of $\mathrm{H}_{2} \mathrm{SO}_{4}$ (Pierce et al. 2010; Vattioni et al. 2019). The final $\boldsymbol{S O}_{2}$ scenario thus assumes the delivery of $20 \mathrm{Mt} \mathrm{SO}_{2} \mathrm{yr}^{-1}(10 \mathrm{Mt} \mathrm{S})$ at the same altitudes and latitudes as the $\mathrm{H}_{2} \mathrm{SO}_{4}$ scenarios at a $D R$ that is as large as technically possible. A summary of the setup of all scenarios is reported in the first part of Table 1 .

Table 1 Main aspects of the delivery scenarios. The dashed horizontal line separates inputs from outputs

\begin{tabular}{lllll}
\hline Scenario & $\boldsymbol{C I}$ & $\boldsymbol{F I}$ & OFI & $\boldsymbol{S O}_{2}$ \\
\hline Payload type & $\mathrm{H}_{2} \mathrm{SO}_{4}$ & $\mathrm{H}_{2} \mathrm{SO}_{4}$ & $\mathrm{H}_{2} \mathrm{SO}_{4}$ & $\mathrm{SO}_{2}$ \\
Annual injection $\left[\mathrm{Mt} \mathrm{yr}^{-1}\right]$ & 15 & 15 & 15 & 20 \\
Diffusivity $\left[\mathrm{m}^{2} \mathrm{~s}^{-1}\right]$ & $10^{2}$ & $10^{2}$ & $3.16 \cdot 10^{2}$ & - \\
Initial concentration $\left[\mathrm{cm}^{-3}\right]$ & $10^{16}$ & $10^{16}$ & $3.16 \cdot 10^{17}$ & - \\
Bypass injection & $\mathrm{No}$ & $\mathrm{Yes}$ & $\mathrm{Yes}$ & - \\
$D R\left[\mathrm{kgm}^{-1}\right]$ & 0.002 & 0.02 & 0.5 & - \\
Altitude $[\mathrm{km}]$ & $20-20.5$ & $20-20.5$ & $20-20.5$ & 20 \\
Payload/flight [tons] & 6.80 & 21.1 & 28.9 & 29.6 \\
Delivery range $[\mathrm{km}]$ & 3370 & 1230 & 53.1 & 10.0 \\
Fuel/flight [tons] & 30.9 & 16.7 & 8.94 & 8.12 \\
Airports & 4.00 & 4.00 & 4.00 & 4.00 \\
Flights/day & 6040 & 1950 & 1420 & 1850 \\
Fleet size & 2360 & 475 & 233 & 286 \\
\hline
\end{tabular}




\subsection{Coupled aircraft/flight profile design}

The simultaneous optimisation of the aircraft configuration and flight profiles described in part 1 resulted in an unmanned aircraft featuring a large, slender, strut-braced wing and four custom-designed turbofan engines. For the direct injection scenarios, $\mathrm{H}_{2} \mathrm{SO}_{4}$ is kept at high temperature onboard and evaporated upon injection into a single outboard engine plume. The main characteristics of the operation that results for each of our scenarios are summarised in the second portion of Table 1 .

The flight profiles of the $\boldsymbol{C I}, \boldsymbol{F I}$ and $\boldsymbol{O F I}$ scenarios have a similar main structure, consisting of an initial climb to the outgoing dispersion leg at $20 \mathrm{~km}$, followed by a second climb to the return dispersion leg, located $500 \mathrm{~m}$ above its outgoing counterpart. Operations are constrained by a critical flight condition encountered during climb. High lift and high thrust requirements can both become critical here $\left(C_{L, c r i t}, T_{c r i t}\right)$ and constrain the payload the aircraft can carry; in practice, the $T_{\text {crit }}$ limit is reached first in these scenarios (see Section 4.2 .2 of part 1 for a more detailed description of these limits). The $\boldsymbol{S O}_{2}$ scenario is simpler, in that it only consists of a climb to $20 \mathrm{~km}$ altitude, the quick release of all payload and return to the airport. However, even in this scenario, the climb is constrained by the $T_{\text {crit }}$ condition. Correspondingly, in the following analyses of financial cost and $\mathrm{CO}_{2} \mathrm{eq}$ emission, the high-performance limit is set by the $T_{\text {crit }}$ condition in the flight profile.

\section{Financial cost analysis}

\subsection{Cost model description}

The estimation of financial cost is based on Raymer's 1999 adjustment of Rand Corporation's Development and Production Costs of Aircraft (DAPCA) model. This method uses statistical cost estimation relationships (CERs) to separately determine initial cost (consisting of research, development, testing and evaluation - RDT\&E - and production cost) and annual operating cost and is commonly used at the conceptual design stage of transport aircraft (Raymer 1999). The relations comprising the model are detailed in McClellan et al. (2010).

The CERs provide either cost for a particular development phase or labour hours for different professions involved (e.g. production materials CERs have cost as an output, whereas RDT\&E engineering CERs provide engineer labour hours). In order to convert labour hours to cost, we use labour rates for the corresponding profession obtained from the U.S. Bureau of Labour statistics, May 2017 National Occupational Employment and Wage Estimates United States (Bureau of Labor Statistics U.D.o.L. 2017b). These are multiplied by a factor 2.5 (Raymer 1999) to give a conservative estimate of the hourly wrap rates, which are tabulated in the supplementary material. The wrap rates are multiplied by 1.03 to convert FY2017 to FY2018 USD (Bureau of Labor Statistics U.D.o.L. 2017a). To estimate pilot labour costs, which deviate from standard practice due to the unmanned concept, one operator is assumed to control four unmanned aircraft. Direct cost outputs are multiplied with 1.51 to convert FY1999 to FY2018 USD (Bureau of Labor Statistics U.D.o.L. 2017a). Moderate changes in labour rates do not have a large impact on total costs.

Raymer's RDT\&E and production equations were scaled by a technological implementation factor (TIF) of 1.5 to incorporate expected cost increases due to difficulties resulting from the extremity of the design and material costs were scaled by a factor of 1.5 to account for the use of the relatively expensive composite material in the aircraft's wings. 
Furthermore, the custom-developed, high-performance turbofan engine's RDT\&E and production cost incorporates a difficulty factor of 2 and scales with the high maximum thrust; the engine's maintenance cost is also affected by these factors (McClellan et al. 2010). For the initial cost of adjustment of airports to SAI operations, a fixed investment of 0.6 B USD per airport was assumed. This was based on the total investment as of 2017 of Deutsche Post DHL group for their recent Central Asia cargo hub at Hong Kong International Airport (DHL press 2017). Although the annual mass of cargo to be handled per airport in the scenarios featuring injection of $15 \mathrm{Mt}$ aerosol $\mathrm{yr}^{-1}$ is larger than the DHL hub capacity, it is assumed that the simple nature of the cargo and infrastructure required as well as standardisation will keep the costs comparable.

Operating cost was estimated using Raymer's method for commercial aircraft (Raymer 1999), motivated by the similarly high flight frequency in airline operations and in our scenarios. The fuel price and the aerosol payload price input parameters were set to 90 USD $\mathrm{bbl}^{-1}$ and $350 \mathrm{USD}^{-1}$, respectively (International Air Transport Association 2018; Boyd 2014). Although commercial prices for $\mathrm{H}_{2} \mathrm{SO}_{4}$ and $\mathrm{SO}_{2}$ differ, we use the same aerosol price for all four scenarios for the sake of comparison. Commercial market $\mathrm{SO}_{2}$ prices are higher than $\mathrm{H}_{2} \mathrm{SO}_{4}$ prices, implying that the reported financial cost of the $\boldsymbol{S O}_{2}$ scenario might be an underestimation. However, it is also likely that commercial prices do not hold for operations at this scale.

In addition to the parameters mentioned, the annual delivery requirement of $15 \mathrm{Mt} \mathrm{yr}^{-1}$ and the payload per flight govern the number of flights, fleet size and number of airports needed for the delivery scenario in question, which make up the scenario-dependent inputs to the cost model.

\subsection{Financial cost over an interval of $D R$}

Since the financial cost is a strong function of the chosen payload-delivery range combination, cost estimates for an annual delivery rate of $15 \mathrm{Mt} \mathrm{H}_{2} \mathrm{SO}_{4} \mathrm{yr}^{-1}$ were made for a matrix of payload-delivery range combinations, obtained using repeated aircraft-flight optimisations as described in part 1 . The matrix spanned an interval which included the $\boldsymbol{C I}, \boldsymbol{F I}$ and $\boldsymbol{O F I} \mathrm{H}_{2} \mathrm{SO}_{4}$ delivery scenarios. The results are shown in Fig. $1 \mathrm{a}$ and b, respectively, where the initial and operating costs are indicated by colour bands. We also include contour lines along which $D R$ - and thus the ratio of payload to delivery range-is constant.

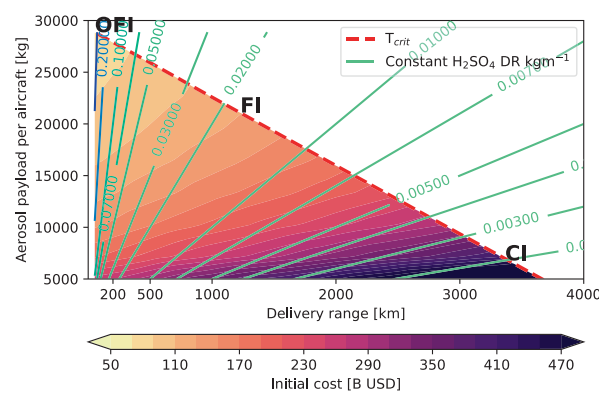

(a) Initial financial cost

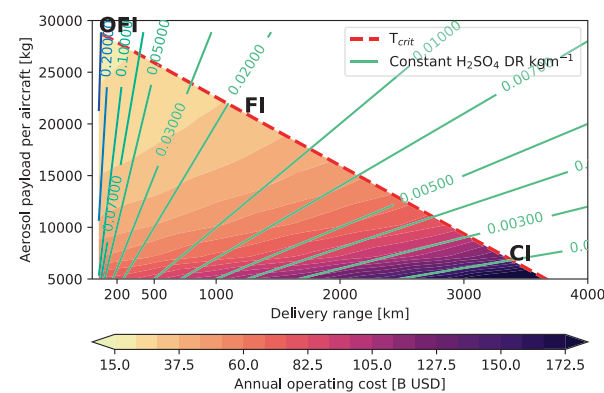

(b) Operating financial cost

Fig. 1 Initial (a) and annual operating (b) financial cost of direct $\mathrm{H}_{2} \mathrm{SO}_{4}$ injection as a function of payload and delivery range combinations constrained by $\mathrm{T}_{\text {crit }}$. The three specific scenarios for targeted initial particle growth under different conditions are annotated 
Modifying payload and delivery range affects the aircraft's take-off weight, which impacts the thrust requiredat the end of the climb segment. Since this cannot exceed $T_{c r i t}$, excessive combinations of payload and delivery range are technically unfeasible. In Fig. 1 $\mathrm{a}$ and $\mathrm{b}$, possible mission scenarios are therefore confined by the broken red line. Changing the take-off weight also impacts take-off $C_{L}$, storage volume, early-flight load cases and margins to aeroelastically unstable modes. However, as none of the these aspects approached their min- or maximum allowed values in the baseline aircraft design, these values were allowed to vary without reexamining their influence on aircraft feasibility.

The cost values for the four scenarios, marked in Fig. 1 a and b, are given in Fig. 2. The figure indicates how initial costs primarily depend on aircraft production related costs, with relatively small airport adjustment and RDT\&E costs, even in the presence of a customdeveloped engine. This is simply due to the high material and labour cost associated with production of a considerable number of aircraft, each having four powerful engines. At large fleet size, the engine production cost constitutes the largest proportion, but this is overtaken by labour costs when the fleet size comes down. Operating cost was found to be primarily determined by maintenance materials cost, which in turn comprises the cost of materials, replacement components and other maintenance supplies. These costs are relatively high for this particular aircraft, due to its extreme design and the specialised high-performance engines. They additionally scale with flight hours and number of sorties, which are also high for SAI aircraft. As the model depends heavily these factors, the operating cost estimate is thought to be relatively conservative. These observations suggest that scenario changes that allow fleet size reductions should be the primary target to bring down initial and operating cost.

Figure $1 \mathrm{a}$ and $\mathrm{b}$ confirm that the most cost-effective payload-range combination for a given prescribed $D R$ lies on the $T_{\text {crit }}$ boundary. For both the initial and operating costs, changes in the prescribed $D R$ are therefore most economically dealt with by changing the delivery range and payload along the $T_{\text {crit }}$ line. It is possible to operate below $T_{\text {crit }}$, but this increases cost through inefficient use of the aircraft's capacity. The three scenarios $\boldsymbol{C I}, \boldsymbol{F I}$ and $\boldsymbol{O F I}$ are therefore positioned on this line. The $\boldsymbol{F I}$ and $\boldsymbol{O F I}$ scenarios achieve substantially lower initial and operating costs than the $\boldsymbol{C I}$ scenario. This is primarily caused
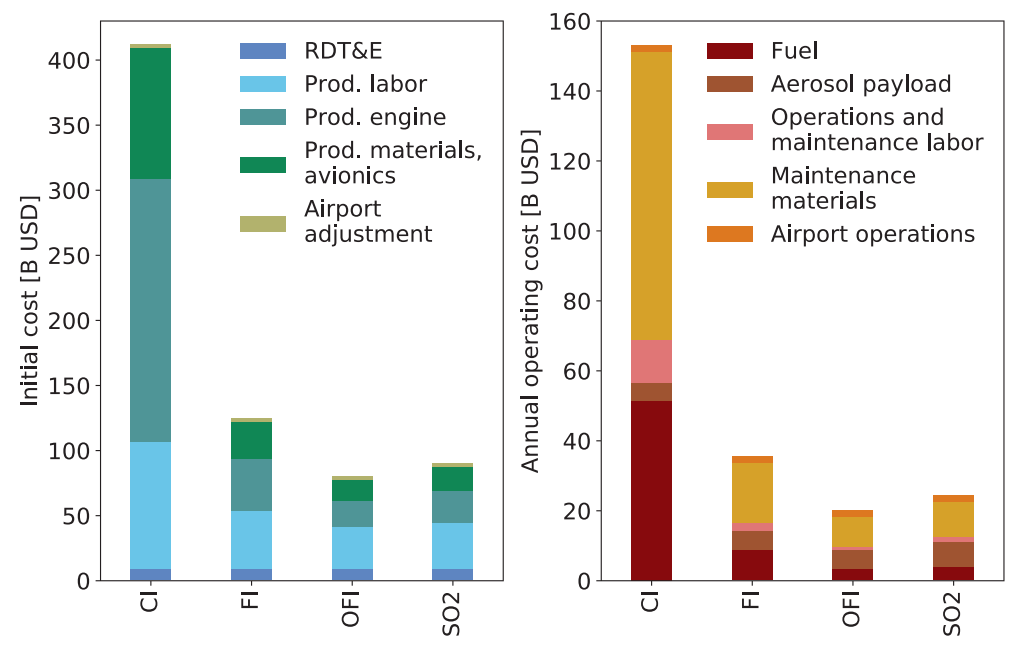

Fig. 2 Comparison and breakdown of initial and operating financial cost for the delivery scenarios 
by the increased $D R$ in the latter two scenarios, allowing for faster aerosol delivery. This results in both lower initial costs due to the reduced size of the fleet of aircraft required and lower operating costs due to lower fleet maintenance requirements and fuel consumption. Consequently, for direct $\mathrm{H}_{2} \mathrm{SO}_{4}$ injection scenarios, the most cost-effective solution is to operate at the point defined by $T_{\text {crit }}$ and maximum achievable $D R$.

Figure 2 directly compares the initial and operating cost of the four scenarios. It shows that if the $\boldsymbol{F I}$ scenario can be realised, the initial costs reduce by $70 \%$ and operating costs reduce by over $75 \%$ with respect to the $\boldsymbol{C I}$ scenario. If the $\boldsymbol{O F I}$ scenario can be achieved, the cost decreases are $80 \%$ and $85 \%$, respectively. This variation spans an order of magnitude in operating cost, and results directly from the uncertainties in achievable plume diffusivity and, consequently, $D R$ that underpin the different scenarios. Therefore, even if the $\boldsymbol{C I}$ scenario may still be considered manageable when compared with e.g. global annual military (Stockholm international peace research institute 2019) or health care (World Health Organization 2019) expenses, there is a strong motivation to research the achievable plume diffusivity for $\mathrm{H}_{2} \mathrm{SO}_{4}$ scenarios in particular and engineering solutions that maximise $D R$ in general.

Figure 2 also includes results for the $\mathrm{SO}_{2}$ scenario. This scenario has no prescribed $D R$ and can therefore operate at the optimum point with minimum delivery range and maximum payload. While cheaper than the $\boldsymbol{C I}$ and $\boldsymbol{F I}$ scenarios, its higher annual aerosol delivery requirement renders it more expensive than the $\mathrm{H}_{2} \mathrm{SO}_{4}$ OFI scenario. As the aerosol payload price was kept the same for the $\boldsymbol{S O}_{2}$ scenario, whereas commercial prices are higher for $\mathrm{SO}_{2}$ than for $\mathrm{H}_{2} \mathrm{SO}_{4}$, the financial cost advantage of the $\boldsymbol{O F I}$ over the $\boldsymbol{S} \boldsymbol{O}_{2}$ scenario might be larger in reality, as aerosol price makes up almost $30 \%$ of the operating cost in the $\boldsymbol{S O}_{2}$ scenario. As there is currently limited knowledge on the relative effectiveness in practice of $\mathrm{SO}_{2}$ and $\mathrm{H}_{2} \mathrm{SO}_{4}$ injection, however, the ultimate ratio of required annual injection rates to achieve a certain effect might differ from the one used here. These factors, along with the ultimately achieved $D R$ in the $\boldsymbol{O F I}$ scenario, will determine their relative costs. As the $\boldsymbol{S O}_{2}$ scenario currently has less uncertainties due to its analog with volcanic emissions, this highlights the need for further research of the $\boldsymbol{O F I}$ scenario, in order to validate its feasibility and the potential benefits of direct $\mathrm{H}_{2} \mathrm{SO}_{4}$ injection in the form of e.g. lower costs and sulphur injection.

In situ production of $\mathrm{SO}_{2}$ has also been proposed (Smith et al. 2018; Smith and Wagner 2018 ), which has the advantage of having to carry only $S$ to stratospheric altitudes. This has the potential to reduce the required annual mass delivery rate. However, the benefits of such a reduction may be somewhat offset by a possible increase in the required aircraft residence time at delivery altitude while S combustion takes place (Smith and Wagner 2018). Still, as this approach has the potential to reduce financial cost, further research on in situ $\mathrm{SO}_{2}$ (or other) aerosol production and delivery should also be pursued.

The observations above pertain to operation variations for the fixed aircraft configuration described in part 1 of this series. Any scenario with a maximum thrust requirement less than the current $T_{\text {crit }}$ value during its critical climb phase would likely benefit from a redesign. This could yield a smaller wing, lower structural and fuel weight, potentially yielding a more conventional design with lower financial cost and $\mathrm{CO}_{2}$ eq emission than the baseline configuration considered here.

Such a more conventional design is presented in Smith and Wagner (2018), which proposes 25 tons of payload can be lofted to $20 \mathrm{~km}$ by an aircraft with a 100 ton take-off weight. With less aggressive climbs and 1 hour of station keeping, the aircraft proposed in Smith and Wagner (2018) would likely achieve this mission at delivery range values which are similar to those of the aircraft presented here. However, our design requires a 150 ton take-off 
weight to do so, which follows directly from the detailed analysis procedures described in part 1 . While the altitude profiles, flight profiles, aerosol species, operating concept, annual delivery target and cost models also differ between the two aircraft, the difference in estimated take-off weight likely plays a major role in the disparity in predicted operating costs for the delivery of 25 tons of payload per flight (approximately 1800 with USD ton ${ }^{-1}$ here, compared with approximately 1400 with USD ton ${ }^{-1}$ in Smith and Wagner (2018)). It will be necessary to fully understand and reduce this disparity to further advance the discussion on the financial implications of developing and operating SAI delivery systems.

\section{$4 \mathrm{CO}_{2}$ eq emission analysis}

Given that SAI's main objective is to curb the detrimental effects brought about by excessive anthropogenic greenhouse gas emissions, it is imperative to quantify the carbon footprint of the SAI delivery system itself. While many aerosol-related aspects of SAI that lead to environmental risks have been studied (Robock 2014), emission figures for specialised aircraft-based SAI delivery systems are to our knowledge missing from the contemporary literature. Therefore, we compute these figures in this section.

As was the case for the financial cost analysis, we distinguish between initial and operating emissions. The following subsections provide quantitative estimates for these two components for the different delivery scenarios. The quantification is made in terms of $\mathrm{CO}_{2}$ eq in order to provide an indication of their relative impact on global warming. The reported $\mathrm{CO}_{2}$ eq values also account for the global warming potential of non- $\mathrm{CO}_{2}$ emissions by using an emission weighting factor (EWF). This approach has some limitations in the current context, as described in Section 4.2.

\subsection{Initial $\mathrm{CO}_{2}$ eq emission}

Estimates of initial $\mathrm{CO}_{2}$ eq emission were made based on emissions due to aircraft development and production, as well as those due to airport construction works.

Emissions due to aircraft development and production were computed using the 2017 average $\mathrm{CO}_{2}$ eq estimate for large airliners described in Airbus (2017), multiplied by the required fleet size. Emissions due to airport modification are based on the conservative assumption that the operation will use existing airports that are complemented with an additional runway and with extended ground facilities to accommodate the added number of flights and logistics required for SAI. The associated $\mathrm{CO}_{2}$ eq estimates were then obtained from the analysis of airport expansions performed in Sturgis Carbon Profiling LLP (2013) (note that there are also local health effects resulting from $\mathrm{NO}_{x}$ emissions due to construction work, but these are not included here). The resulting initial $\mathrm{CO}_{2}$ eq emission estimates for all four scenarios appear in the first part of Fig. 4.

\subsection{Operating $\mathrm{CO}_{2}$ eq emission}

Estimates of operating $\mathrm{CO}_{2}$ eq emission were obtained by adding the emissions of running the required airport facilities to those associated with aircraft operation. Airport facility $\mathrm{CO}_{2}$ eq emissions were estimated using reference data for existing airports which handle around 400,000 aircraft movements per year, which is on the order of magnitude of the annual number of flights per airport in the $\boldsymbol{C I}$ scenario and is thus conservative for all other scenarios which feature lower flight numbers (Federal Aviation Administration 2017). 
The annual $\mathrm{CO}_{2}$ eq emissions associated with in-flight aircraft operation result from estimates of $\mathrm{CO}_{2}$ emissions, which are scaled by an EWF. $\mathrm{CO}_{2}$ emissions are computed by multiplying the total fuel consumption of a scenario (obtained from our aircraft model) with the amount of $\mathrm{CO}_{2}$ released per kg fuel burned: a constant value of 3.16 (Penner et al. 1999). In contrast, determining an adequate EWF is not trivial, due to the complex interaction of aircraft engine combustion products with the environment.

In addition to $\mathrm{CO}_{2}$, aircraft engine combustion produces $\mathrm{H}_{2} \mathrm{O}$ and $\mathrm{NO}_{x}$, as well as aerosol particles consisting of e.g. soot, sulphate and hydrocarbons. The impact of these emissions depends on the altitude at which they are emitted as well as local conditions. Emitted $\mathrm{H}_{2} \mathrm{O}$ can produce contrails in the troposphere, which both reflect solar radiation and trap thermal radiation. Generally, their net effect on the earth's surface is warming (Azar and Johansson 2012). Stratospheric warming due to heat absorption by emitted water vapour and particulate matter can further increase stratospheric water vapour content and lead to ozone depletion, intensifying the earth's surface warming due to increased solar radiation passing through the atmosphere (Azar and Johansson 2012; Heckendorn et al. 2009). In contrast, $\mathrm{NO}_{x}$ emitted at high tropospheric altitudes typically results in increased ozone formation. Another effect of high altitude $\mathrm{NO}_{x}$ is methane depletion, which, on longer time scales, results in decreased ozone concentrations, in contrast to the initial $\mathrm{NO}_{x}$ effect. The initial $\mathrm{NO}_{x}$ ozone/methane response thus has a net cooling effect, but this effect reverses as time progresses (Azar and Johansson 2012). The aerosols produced by combustion can have a reflection-induced cooling effect, although this depends on the balance of their specific radiative properties and their tendency to promote contrail formation. Generally, their effect on warming is uncertain and dependent on local conditions (IPCC 2013).

Due to i.a. these complexities and the different economic and physical metrics available (see Azar and Johansson 2012), the EWF values for aviation span a large range. They typically vary between 1.3 and 2.9 for operations as considered here, with a best estimate of 1.7 when using global warming potential as the relevant metric (Azar and Johansson 2012). Therefore, we use an EWF of 1.7 in our computations.

The resulting operating $\mathrm{CO}_{2}$ eq emission estimates for all four scenarios appear in the second part of Fig. 4. As before, local health effects due to $\mathrm{NO}_{x}$ emissions from ground operations are not accounted for.

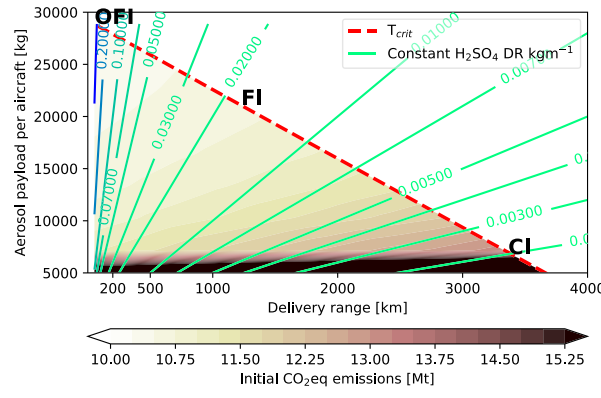

(a) Initial $\mathrm{CO}_{2} \mathrm{eq}$ emission

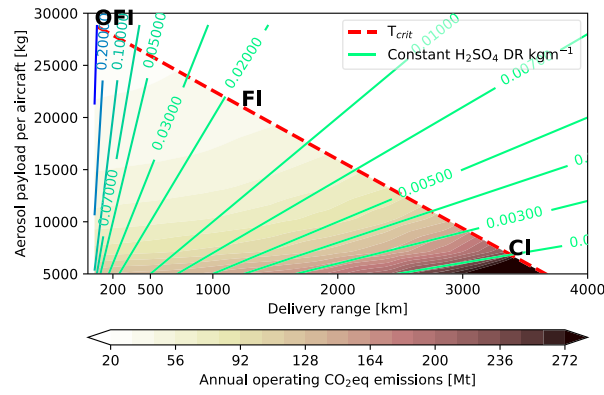

(b) Operating $\mathrm{CO}_{2}$ eq emission

Fig. 3 Initial (a) and annual operating (b) equivalent $\mathrm{CO}_{2}$ emissions of direct $\mathrm{H}_{2} \mathrm{SO}_{4}$ injection as a function of payload and delivery range combinations constrained by $\mathrm{T}_{\text {crit }}$. The three specific scenarios for targeted initial particle growth under different conditions are annotated 


\section{3 $\mathrm{CO}_{2}$ eq emission over an interval of $D R$}

Similar to the estimates of financial cost, the estimates of $\mathrm{CO}_{2}$ eq emission are highly sensitive to payload and range, which in turn are a function of $D R$. Thus, plots of initial and operating $\mathrm{CO}_{2}$ eq emission for the same range of conditions considered in Section 3.2 are given in Fig. $3 \mathrm{a}$ and $\mathrm{b}$. The $\mathrm{CO}_{2}$ eq emission follows trends similar to those of the financial cost: high $D R$ scenarios have smaller initial and operating $\mathrm{CO}_{2}$ eq emission due to fleet size reductions and lower fuel consumption. A sharp increase in initial $\mathrm{CO}_{2}$ eq emission is seen for payload values below $\approx 6$ tons, which is due to an increase in the number of airports required to accommodate the increasing number of flights per day for lower flight payloads.

A difference between $\mathrm{CO}_{2}$ eq emission and financial cost behaviour is seen for very low $D R \mathrm{~s}$. Here, possible delivery scenarios below the $T_{\text {crit }}$ line have moderately lower operating $\mathrm{CO}_{2}$ eq emission at constant $D R$, as fuel savings per flight for smaller payload and delivery range combinations slightly outweigh the extra fuel required by the increased flight numbers of such combinations. However, this difference is small.

The $\mathrm{CO}_{2}$ eq emission breakdown in Fig. 4 shows how both initial and operating $\mathrm{CO}_{2}$ eq emissions are largely determined by a single component. Initial $\mathrm{CO}_{2} \mathrm{eq}$ is dominated by airport construction related emissions, which scales with the number of airports required to support the required fleet size. The number of airports is constant; four airports can accommodate each of the four scenarios. However, since fleet size decreases as $D R$ increases across the scenarios, the relative contribution of aircraft development and production to initial $\mathrm{CO}_{2}$ eq emission decreases. The airport modification emission estimates are based on conservative values from literature and could turn out to be lower in reality. However, this is unlikely to significantly affect the total $\mathrm{CO}_{2}$ eq emission, since for a mission spanning several years, it would clearly be dominated by the operating $\mathrm{CO}_{2}$ eq emission.

Operating $\mathrm{CO}_{2}$ eq is essentially determined by fuel combustion. The percentage contribution of this parameter decreases as $D R$ increases, but only very slightly. Given the large fuel-related contributions to both operating financial cost and $\mathrm{CO}_{2}$ eq emission $(>17 \%$ and $>99 \%$ respectively in $\boldsymbol{O F I}$ ), it is once again important to attain high $D R$ s to reduce range and flight numbers. This is also clearly demonstrated in Fig. 4, which shows large reductions in $\mathrm{CO}_{2}$ eq for the $\boldsymbol{F I}$ and $\boldsymbol{O F I}$ scenarios. The figure also shows that, like the financial cost, the $\mathrm{CO}_{2}$ eq emission of $\boldsymbol{O F I}$ is similar to that of $\boldsymbol{S O}_{2}$.
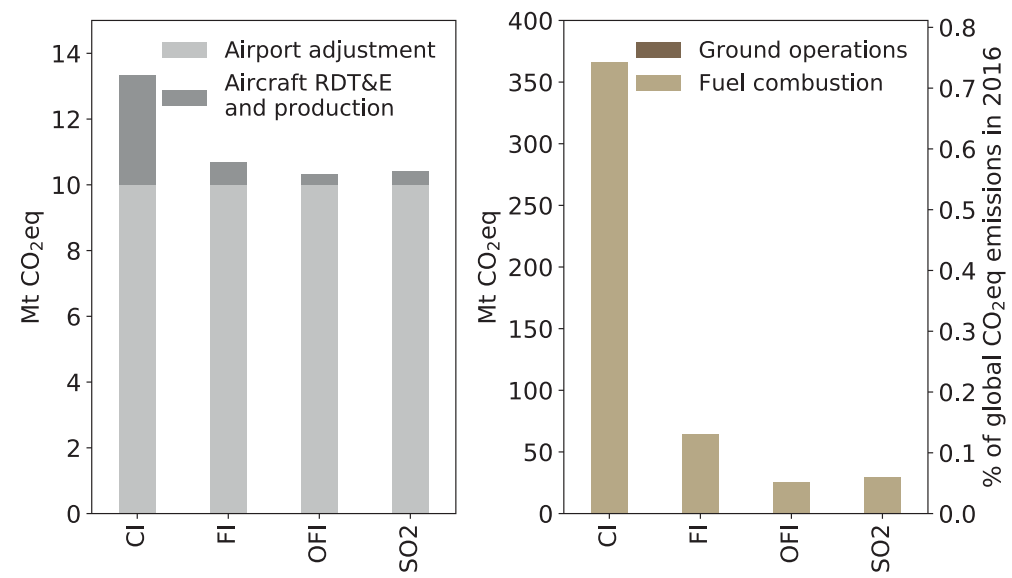

Fig. 4 Breakdown of initial and operating $\mathrm{CO}_{2}$ eq emission for the delivery scenarios 
An indication of the relative impact of the proposed delivery method is given on the rightmost $y$-axis in Fig. 4, which shows the operating $\mathrm{CO}_{2}$ eq emission as a percentage of the global annual $2016 \mathrm{CO}_{2}$ eq emission (Olivier et al. 2017). The values are appreciable for a single aeronautical operation, especially for scenarios that deviate far from $\boldsymbol{O F I}$. While the corresponding effect is still rather small relative to the beneficial anticipated cooling effects of the delivered aerosol, this again indicates the importance of development of high $D R$ technologies.

\section{Sensitivity analysis}

Aside from the uncertainties in the achievable $D R$, the analyses presented in the previous sections depend on a number of input parameters to our model that are also subject to uncertainty. In the following, the most important of these are listed and the sensitivity of financial cost and $\mathrm{CO}_{2}$ eq emission to their variation is quantified and briefly discussed. In the supplementary material, the complete, detailed version of this sensitivity analysis is provided. The sensitivity of financial cost and $\mathrm{CO}_{2}$ eq emission to design choices, i.e. propulsion system and operating altitude, as described in part 1 , is also presented in the supplementary material.

For the sensitivity analysis, $D R$ and critical climb segments are kept constant; less critical flight phases are allowed to change. Hence, perturbations in design parameters drive changes to the payload-range combinations (along a $D R$-isoline) and the coupled procedure is iterated until either the thrust constraint imposed by $T_{c r i t}$ or the lift constraint imposed by $C_{L, \text { crit }}$ is encountered. The resulting payload-range combination can be unambiguously translated into changes in operating parameters and financial cost and $\mathrm{CO}_{2} \mathrm{eq}$ emission.

The results of the sensitivity analysis are only presented for the $\boldsymbol{C I}$ scenario. The general conclusions remain similar for the other scenarios, although the specific magnitudes resulting from the analysis differ.

\subsection{Input parameters}

The following six parameters and perturbations have been considered.

1. Annual aerosol delivery

Range $50-150 \%$ of baseline value

2. Operational empty weight (OEW)

Range $90-110 \%$ of baseline value

3. Specific fuel consumption (SFC)

Range $80-120 \%$ of baseline value

4. Technological implementation factor (TIF)

Range 1-2

5. Fuel price

Range 60-120 USD bbl ${ }^{-1}$ (International Air Transport Association 2018)

6. Payload price

Range 250-450 USD ton ${ }^{-1}$ (Boyd 2014)

Several other aircraft and cost-model related inputs were also examined for their effects on financial cost and $\mathrm{CO}_{2} \mathrm{eq}$ emission, but were found to be of minor importance in comparison with those listed. 


\subsection{Sensitivity of financial cost}

The changes in financial cost of the $\boldsymbol{C I}$ scenario due to individual variations of the input parameters are summarised in Fig. 5.

Annual aerosol delivery impacts both initial and operating cost by increasing the fleet size and number of flights required. In total, a 50\% increase and decrease in annual aerosol delivery lead to a $39.9 \%$ increase and $42.1 \%$ decrease in initial cost, respectively, and a $48.8 \%$ increase and $48.9 \%$ decrease in operating cost, respectively.

OEW variations also notably affect the financial cost of the system, primarily through large changes in the fleet size and number of flights. This is a result of the extreme operating conditions leading to low payloads that quickly decrease if aircraft efficiency is reduced. Around the $\boldsymbol{C I}$ scenario, $10 \%$ increases and decreases in OEW lead to $29.5 \%$ and $-13.2 \%$ changes to initial costs and $28.3 \%$ and $-11.1 \%$ changes in operating costs. During the aircraft development cycle, minimising the weight of the aircraft components should thus be assigned appropriate importance, especially given the higher sensitivity to cost-increasing OEW increases.

The sensitivity of operating cost to a $20 \%$ SFC decrease is $-11.8 \%$, while a $20 \%$ increase leads to a $15.2 \%$ increase. These values are remarkably moderate for a $20 \%$ variation in input parameter value. This is a positive finding, as the robustness of cost to SFC increases the viability of the development and use of custom engines with comparatively high SFC uncertainties.

Despite a relatively large TIF interval, its effect on initial cost is moderate, amounting to $\mathrm{a} \pm 9.16 \%$ variation over the interval considered. This again increases the economic viability of developing custom technology for the system.

The last parameters considered, fuel price and payload price, do not significantly affect operating cost, as operating cost is dominated by the maintenance materials cost. In the more optimised direct $\mathrm{H}_{2} \mathrm{SO}_{4}$ injection scenarios and the $\mathrm{SO}_{2}$ scenario, the contribution of payload cost to the operating financial cost increases substantially (up to $26 \%$ for $\boldsymbol{O F I}$ ). In such scenarios, payload cost might be an important factor, but is not expected to fatally affect feasibility.
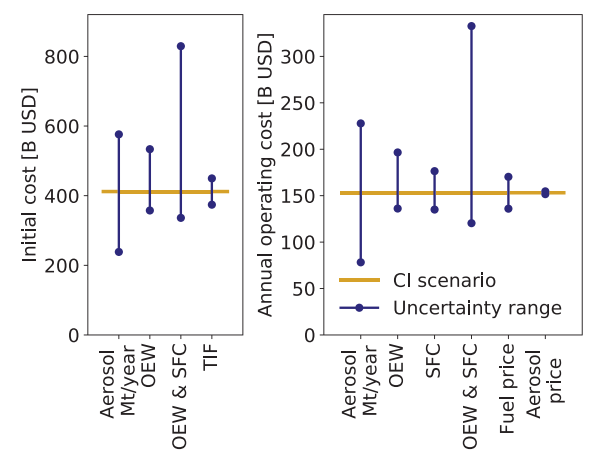

(a) Financial cost sensitivity
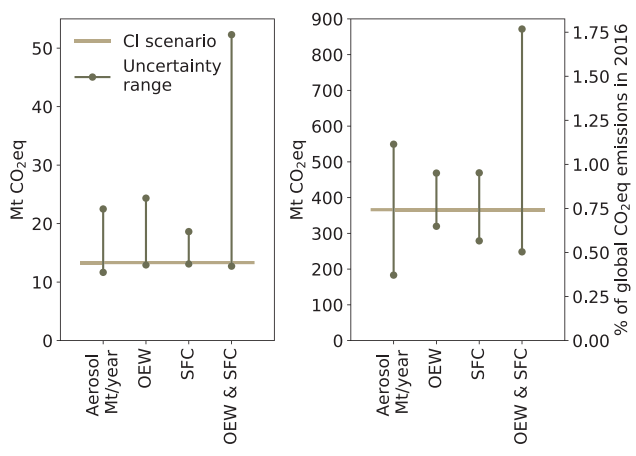

(b) $\mathrm{CO}_{2}$ eq sensitivity

Fig. 5 Sensitivity of financial cost (a) and $\mathrm{CO}_{2}$ eq emission (b) to variations in uncertain input parameters for the $\boldsymbol{C I}$ scenario. Variations in input parameters are accommodated by changes in the weight budget of the aircraft, leading to new payload-delivery range combinations whilst keeping $D R$ constant and changes in the associated injection scenario parameters 


\subsection{Sensitivity of $\mathrm{CO}_{2}$ eq emission}

The changes in $\mathrm{CO}_{2}$ eq emission of the $\boldsymbol{C I}$ scenario due to individual variations of the input parameters are summarised in Fig. 5a.

Increases in the annual aerosol delivery rate affect the initial $\mathrm{CO}_{2} \mathrm{eq}$ emission due to the increased number of airports required for the $\boldsymbol{C I}$ scenario. Increases in OEW and SFC also increase the number of required flights and thus the number of airports and initial $\mathrm{CO}_{2}$ eq emission. As the $\boldsymbol{C I}$ scenario already employs the minimum number of airports (four), decreases in annual aerosol delivery rate, OEW or SFC have very little impact.

Changes in operating $\mathrm{CO}_{2}$ eq emission due to changes in annual aerosol delivery, OEW and SFC are more substantial. The first of these scales the overall mission, while OEW and SFC affect the amount of payload which can be carried per flight. Increases in any of these inputs thus increase the number of flights required and hereby fuel consumption, the main factor determining operating $\mathrm{CO}_{2}$ eq emission.

Increasing or decreasing the annual aerosol delivery by $50 \%$ changes the operating $\mathrm{CO}_{2}$ eq emission by $50.0 \%$ and $-50.0 \%$. The operating $\mathrm{CO}_{2}$ eq emission is more sensitive to increases than to decreases in OEW, amounting to $+28.0 \%$ and $-12.7 \%$ changes, respectively. Increases in SFC result in more fuel burned per flight and consequently more emissions, but also flight number increases occur, as the fuel weight increases at the expense of payload weight per flight. A $20 \%$ increase or decrease in SFC thus produces changes of $+28.2 \%$ and $-23.8 \%$ in operating $\mathrm{CO}_{2}$ eq emission, respectively. For both OEW and SFC, the larger upward sensitivity is due to the low $\boldsymbol{C I}$ payload, as was the case for financial cost sensitivity.

As the $\mathrm{CO}_{2}$ eq emission of $\boldsymbol{C I}$ is significant, achieving a low $\mathrm{OEW}$ and fuel consumption is highly desirable for this scenario. This is also important for the $\boldsymbol{F I}$ and $\boldsymbol{O F I}$ scenarios, for which fuel makes up a larger fraction of the operating $\mathrm{CO}_{2}$ eq emission. However, in $\boldsymbol{F I}$ and $\boldsymbol{O F I}$, the relative impact is small compared with other greenhouse gas sources.

\subsection{Sensitivity to combined uncertainties}

The sensitivities presented in the previous section were evaluated by considering uncertainties in each input parameter separately. This is appropriate for most cases, as the effects of uncertainties in the majority of the parameters are independent of each other (e.g. those

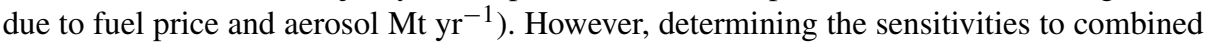
uncertainties in OEW and SFC is more complex, as their effects are strongly coupled via the flight profile optimisation procedure. Therefore, Fig. 5 also includes estimates of the sensitivities to simultaneous $10 \%$ and $20 \%$ changes to OEW and SFC, respectively. The plotted bar shows the extremes, when both changes have the same sign.

Lower OEW and SFC lead to financial cost and $\mathrm{CO}_{2}$ eq reductions that do not exceed the sum of their individual effects. This is because this scenario simultaneously exchanges aircraft empty weight for payload and allows longer ranges to be flown at the same fuel weight. Yet, the increasing range required for increasing payload at constant $D R$ limits cost and emission decreases by increasing fuel required. Hence, the effect of the combined variation is moderate.

Combined increases in OEW and SFC are more problematic, as the payload per flight becomes so low that flight numbers and fleet size become very high. Fleet size and flight number increases are causative of the major part of cost variations and operating $\mathrm{CO}_{2} \mathrm{eq}$ variations, whereas the increase in initial $\mathrm{CO}_{2} \mathrm{eq}$ is primarily due to the higher number of airports required. The amplification effects are considerable, leading to $>100 \%$ increases in 
initial and operation costs and $\mathrm{CO}_{2}$ eq. These are approximately double the summed effects of individual OEW and SFC variations. As the aircraft configuration in part 1 was designed using validated models, it is unlikely that the actual variations in OEW and SFC will exceed a few percent. However, it will be highly important that the final aircraft design process monitors these variations closely.

\section{Conclusions and recommendations}

This paper has presented the financial cost and $\mathrm{CO}_{2}$ eq emission analyses for the relatively detailed SAI delivery system developed in part 1 of this series. These have been performed for scenarios considering the direct injection of $\mathrm{H}_{2} \mathrm{SO}_{4}$, as well as $\mathrm{SO}_{2}$ injection. The $\mathrm{SO}_{2}$ injection scenario is relatively simple, as its financial cost and $\mathrm{CO}_{2}$ eq emission are primarily determined by the number of flights and aircraft required and are thus minimised when payload per flight is maximised. The situation is more complex for direct $\mathrm{H}_{2} \mathrm{SO}_{4}$ injection, which requires specific combinations of initial $\mathrm{H}_{2} \mathrm{SO}_{4}$ concentration and plume diffusivity to produce favourably sized aerosol particles. The results demonstrate that the financial cost and $\mathrm{CO}_{2}$ eq emission of direct $\mathrm{H}_{2} \mathrm{SO}_{4}$ injection decrease strongly with increasing dispersion rate $(D R)$.

High $D R$ allows shorter flights that carry more payload, reducing the required fleet size and fuel consumption to achieve a given delivery target. As fleet size is the single largest contributor to financial cost, and fleet size and fuel consumption drive $\mathrm{CO}_{2}$ eq emission, maximising $D R$ minimises both. This is illustrated by three $\mathrm{H}_{2} \mathrm{SO}_{4}$ injection scenarios with varying assumptions on engine exhaust injection volume and diffusivity. For the very conservative $\boldsymbol{C I}$ scenario, cost and emissions are relatively high, 412 and 153 B USD for initial and annual operating financial costs, and 13.3 and $366 \mathrm{Mt} \mathrm{CO}_{2} \mathrm{eq}$ for initial and annual operating $\mathrm{CO}_{2}$ eq emissions. For the likely achievable $\boldsymbol{F I}$ scenario, this drops to 124 and $35.5 \mathrm{~B}$ USD, with 10.7 and $64.1 \mathrm{Mt} \mathrm{CO}_{2}$ eq. For the more optimistic $\boldsymbol{O F I}$ scenario, the numbers become quite low: 80.1 and 20.3 B USD with 10.3 and $25.2 \mathrm{Mt} \mathrm{CO}_{2}$ eq. The values for this latter $\mathrm{H}_{2} \mathrm{SO}_{4}$ scenario appear comparable with those associated with $\mathrm{SO}_{2}$ injection, under the assumption that $\mathrm{SO}_{2}$ injection requires twice as much annual $\mathrm{S}$ delivery. An analysis of realistic value ranges for uncertain input parameters indicates that the above conclusions are robust.

The strong sensitivity of financial cost and $\mathrm{CO}_{2}$ eq emission to $D R$ motivates a more detailed treatment of the assumptions underpinning our direct $\mathrm{H}_{2} \mathrm{SO}_{4}$ injection scenarios. In particular, a more detailed understanding of aerosol growth in realistic aircraft plumes, what levels of diffusivity can be attained in such plumes by engineering and the resulting impact on achievable $D R$, could narrow the uncertainty margins in these numbers considerably. This may in turn better inform trade-offs between direct $\mathrm{H}_{2} \mathrm{SO}_{4}$ injection and $\mathrm{SO}_{2}$ injection.

Although only part of the foreseen and unforeseen effects of SAI are covered in this study, the anticipated financial cost and $\mathrm{CO}_{2}$ eq emissions of developing and operating a fleet of specialised aircraft for direct $\mathrm{H}_{2} \mathrm{SO}_{4}$ injection can be considered to be manageable, and will likely be substantially outweighed by SAI's intended economic and environmental effects.

Open Access This article is licensed under a Creative Commons Attribution 4.0 International License, which permits use, sharing, adaptation, distribution and reproduction in any medium or format, as long as you give appropriate credit to the original author(s) and the source, provide a link to the Creative Commons licence, and indicate if changes were made. The images or other third party material in this article are included 
in the article's Creative Commons licence, unless indicated otherwise in a credit line to the material. If material is not included in the article's Creative Commons licence and your intended use is not permitted by statutory regulation or exceeds the permitted use, you will need to obtain permission directly from the copyright holder. To view a copy of this licence, visit http://creativecommonshorg/licenses/by/4.0/.

\section{References}

Airbus (2017) Reporting and performance data. Retrieved from: www.airbus.com/company/responsibilitysustainability

Azar C, Johansson DJA (2012) Valuing the non-CO2 climate impacts of aviation. Clim Chang 111(3):559_ 579

Benduhn F, Schallock J, Lawrence MG (2016) Early growth dynamical implications for the steerability of stratospheric solar radiation management via sulfur aerosol particles. Geophys Res Lett 43(18):99569963

Boyd F (2014) Global sulfuric acid market: a twenty year retrospective. Tech. rep., Argus Media

Crutzen PJ (2006) Albedo enhancement by stratospheric sulfur injections: a contribution to resolve a policy dilemma? Clim Change 77(3):211-220

DHL press (2017) DHL announces HKD 2.9 billion expansion plan for its central Asia hub in Hong Kong. Retrieved from: www.dhl.com.hk/en/press/releases/releases_2017

DSE Group 02 (2016) A delivery system for stratospheric aerosol geoengineering. Tech. rep., Delft University of Technology

Dykema J, Keith D, Keutsch F (2016) Improved aerosol radiative properties as a foundation for solar geoengineering risk assessment. Geophys Res Lett 43(14):7758-7766

Federal Aviation Administration (2017) Airport carbon emissions reduction. Retrieved from: www.faa.gov/ airports/environmental

Heckendorn P, Weisenstein D, Fueglistaler S, Luo BP, Rozanov E, Schraner M, Thomason LW, Peter T (2009) The impact of geoengineering aerosols on stratospheric temperature and ozone. Environ Res Lett 4(4):108-120

International Air Transport Association (2018) Jet fuel price monitor. Retrieved from: www.iata.org/ publications/economics/fuel-monitor

IPCC (2013) Climate change 2013: The physical science basis. Contribution of working group i to the fifth assessment report of the intergovernmental panel on climate change cambridge university press

IPCC (2018) IPCC special report: global warming of 1.5C - chapter, vol 1. Cambridge University Press, Geneva

Irvine PJ, Kravitz B, Lawrence MG, Muri H (2016) An overview of the earth system science of solar geoengineering. Wiley Interdiscip Rev Clim Chang 7(6):815-833

Keith DW, Weisenstein DK, Dykema JA, Keutsch FN (2016) Stratospheric solar geoengineering without ozone loss. Proc Natl Acad Sci 113(52):14,910-14,s914

Kravitz B, Caldeira K, Boucher O, Robock A, Rasch PJ, Alterskjær K, Karam DB, Cole JN, Curry CL, Haywood JM et al (2013) Climate model response from the geoengineering model intercomparison project (GeoMIP). J Geophy Res Atmos 118(15):8320-8332

Bureau of Labor Statistics U.D.o.L. (2017) Consumer price index, inflation calculator. Retrieved from www. bls.gov/cpi

Bureau of Labor Statistics U.D.o.L. (2017) May 2017 national occupational employment and wage estimates united states. Retrieved from www.bls.gov/oes

Latham J, Bower K, Choularton T, Coe H, Connolly P, Cooper G, Craft T, Foster J, Gadian A, Galbraith L et al (2012) Marine cloud brightening. Phil Trans R Soc A 370(1974):4217-4262

Lin AC (2013) Does geoengineering present a moral hazard. Ecology LQ 40:673

Lohmann U, Gasparini B (2017) A cirrus cloud climate dial? Science 357(6348):248-249

McClellan J, Sisco J, Suarez BGK (2010) Geoengineering cost analysis final report. Tech. rep., Aurora Flight Sciences

Olivier JGJ, Schure KM, Peters JAHW (2017) Trends in global CO2 and total greenhouse gas emissions. Tech. rep. PBL Netherlands Environmental Assessment Agency, The Hague

Penner JE, Lister DH, Griggs DJ, Dokken DJ, McFarland M (1999) IPCC special report: aviation and the global atmosphere. Cambridge University Press, Geneva

Pierce JR, Weisenstein D, Heckendorn P, Peter T, Keith DW (2010) Efficient formation of stratospheric aerosol for climate engineering by emission of condensible vapor from aircraft. Geophy Res Lett 37(18):L18805 
Pope FD, Braesicke P, Grainger RG, Kalberer M, Watson IM, Davidson PJ, Cox RA (2012) Stratospheric aerosol particles and solar-radiation management. Nat Clim Chang 2(10):713-719

Rasch PJ, Tilmes S, Turco RP, Robock A, Oman L, Chen CC, Stenchikov GL, Garcia RR (2008) An overview of geoengineering of climate using stratospheric sulphate aerosols. Philosophical Transactions of the Royal Society of London A: Mathematical. Phys Eng Sci 366(1882):4007-4037

Raymer DP (1999) Aircraft design, a conceptual approach, 3rd edn. American institute of aeronautics and astronautics

Reynolds JL (2019) The governance of solar geoengineering: managing climate change in the Anthropocene. Cambridge University Press

Robock A (2014) Geoengineering of the climate system, stratospheric aerosol geoengineering. Issues in Environmental Science and Technology The Royal Society of Chemistry

Schumann U, Schlager H, Arnold F, Baumann R, Haschberger P, Klemm O (1998) Dilution of aircraft exhaust plumes at cruise altitudes. Atmos Environ 32(18):3097-3103

Shepherd J (2009) Geoengineering the climate: science, governance and uncertainty. Project report

Smith JP, Dykema JA, Keith DW (2018) Production of sulfates onboard an aircraft: implications for the cost and feasibility of stratospheric solar geoengineering. Earth Space Sci 5(4):150-162

Smith W, Wagner G (2018) Stratospheric aerosol injection tactics and costs in the first 15 years of deployment. Environmental Research Letters 13(12):124001

Stockholm international peace research institute (2019) Sipri military expenditure database. Retrieved from: www.sipri.org/databases/milex

Storelvmo T, Kristjansson JE, Muri H, Pfeffer M, Barahona D, Nenes A (2013) Cirrus cloud seeding has potential to cool climate. Geophys Res Lett 40(1):178-182

Sturgis Carbon Profiling LLP (2013) Carbon footprint airports, a proposal to identify the benefits from networked solution to meeting London airport capacity shortage. Tech. rep. Commissioned by Terry Farrell Partnership and Gatwick Airport Limited

Tilmes S, Richter JH, Mills MJ, Kravitz B, MacMartin DG, Vitt F, Tribbia JJ, Lamarque JF (2017) Sensitivity of aerosol distribution and climate response to stratospheric $\mathrm{SO} 2$ injection locations. Journal of Geophysical Research: Atmospheres 122(23):12,591-12,615

Vattioni S, Weisenstein D, Keith D, Feinberg A, Peter T, Stenke A (2019) Exploring accumulation-mode h2SO4 versus $\mathrm{SO} 2$ stratospheric sulfate geoengineering in a sectional aerosol-chemistry-climate model. Atmos Chem Phys 19(7):4877-4897

World Health Organization (2019) Global health expenditure database. Retrieved from: www.apps.who.int/ nha/database

Yu F, Turco RP (1998) The formation and evolution of aerosols in stratospheric aircraft plumes: numerical simulations and comparisons with observations. J Geophys Res Atmos 103(D20):25,915-25,934

Publisher's note Springer Nature remains neutral with regard to jurisdictional claims in published maps and institutional affiliations.

\section{Affiliations}

\section{E. de Vries ${ }^{1}$ - M. Janssens ${ }^{2}$ · S. J. Hulshoff ${ }^{2}$. DSE 16-02}

1 Department of Meteorology, Stockholm University, Svante Arrheniusvägen 16, Stockholm, Sweden

2 Faculty of Aerospace Engineering, Delft University of Technology, Kluyverweg 1, Delft, The Netherlands 